\title{
Metal Organic Framework@Polysilsesequioxane Core/Shell-Structured Nanoplatform for Drug Delivery
}

\author{
Liangyu Lu ${ }^{1}$, Mengyu Ma ${ }^{1}$, Chengtao Gao ${ }^{1,2}$, Hongwei Li $^{1}$, Long Li $^{1}$, Fuping Dong ${ }^{1, *(D)}$ and \\ Yuzhu Xiong 1 ,* \\ 1 College of Materials and Metallurgy, Guizhou University, Guiyang 550025, China; \\ gs.lylu17@gzu.edu.cn (L.L.); mmymamengyu@163.com (M.M.); chengtaogao@163.com (C.G.); \\ lhwnoonoo123@163.com (H.L.); lilong@gzu.edu.cn (L.L.) \\ 2 National Engineering Research Center for Compounding and Modification of Polymer Materials, \\ Guiyang 550025, China \\ * $\quad$ Correspondence: fpdong@gzu.edu.cn (F.D.); yzxiong@gzu.edu.cn (Y.X.); Tel.: +86-15519037121(F.D.); \\ +86-851-83627518 (Y.X.)
}

Received: 15 November 2019; Accepted: 16 January 2020; Published: 25 January 2020

\begin{abstract}
Modern pharmaceutics requires novel drug loading platforms with high drug loading capacity, controlled release, high stability, and good biocompacity. Metal-organic frameworks (MOFs) show promising applications in biomedicine owing to their extraordinarily high surface area, tunable pore size, and adjustable internal surface properties. However, MOFs have low stability due to weak coordinate bonding and limited biocompatibility, limiting their bioapplication. In this study, we fabricated MOFs/polysilsesquioxane (PSQ) nanocomposites and utilized them as drug carriers. Amine-functionalized MOF (UiO-66- $\mathrm{NH}_{2}$ ) nanoparticles were synthesized and encapsulated with epoxy-functionalized polysilsesquioxane layer on the surface via a facile process. MOFs possessed high surface area and regular micropores, and PSQs offered stability, inertness, and functionality. The obtained UiO-66- $\mathrm{NH}_{2} @ E P S Q$ nanocomposites were utilized as carriers for ibuprofen, a drug with carboxylic groups on the surface, and demonstrated high drug loading capacity and well-controlled release property. The UiO-66- $\mathrm{NH}_{2} @ E P S Q$ nanocomposite exhibited low cytotoxicity to HeLa cells within a wide concentration range of $10-100 \mu \mathrm{g} / \mathrm{mL}$, as estimated by the MTT method. The UiO-66- $\mathrm{NH}_{2} @ E P S Q$ drug release system could be a potential platform in the field of controlled drug delivery.
\end{abstract}

Keywords: metal organic framework; organosilica; polysilsesquioxane; drug delivery; surface functionalization

\section{Introduction}

Development of a novel pharmaceutical platform with unique biological properties has gained tremendous academic interest in the field of nanobiomedicine [1,2]. Nanomaterials with a porous structure are widely investigated in biomedicine due to their features, such as suitable architecture, large surface area, and stability in biological fluids [3-9]. Among different types of porous materials, silica, calcium carbonate, calcium phosphate, and metal-organic frameworks (MOFs) have received significant attention in the last decade [10]. Although they are in the early stages of development [11,12], MOFs, wherein metal ions or clusters link organic ligands into porous materials, have shown great promise as a novel nanomedicine platform due to its large surface area, adjustable pore size, tunable host-guest interaction, and versatile functionality $[13,14]$. Preliminary biomedical applications of MOFs have focused on their use as delivery vehicles for molecular therapeutics and as viable contrast 
agents for optical imaging, multimodal imaging or X-ray computed tomography imaging $[15,16]$. In particular, MOFs are very promising nanoscale drug carriers due to their high molecule loading and easy functionalization [17-22]. MOFs have been utilized to deliver drug molecules through attachment of the prodrug onto the framework or direct use of the prodrug as a building block.

In pharmaceutical applications, enhancing the water stability, mechanical strength, and biocompatibility of MOFs while maintaining their other advantages remains a big challenge [23-25]. To solve this problem, researchers have attempted to fabricate MOF nanocomposites with other materials, such as polymers, silica, graphene, or carbon nanotubes, which have different properties, as the reinforcement phase [26-38]. Silica is suitable for preparation of composite materials to improve the performance of MOFs due to its high stability and structural adjustability [39-42]. Silica not only provides structural support for MOFs, but also improves the stability of materials through hydrophobic interaction or covalent bonding [43-45]. The modification of MOF surfaces with silica coatings improves the stability of MOFs, fine tunes their properties, and imparts additional functionality [46]. For example, Lin et al. first stabilized nano-MOFs by encapsulating them within a silica shell; the product offers several advantages, including biocompatibility, increased water dispersibility, and easy functionalization with silyl-derived molecules [47]. In detail, this study first coated MOF nanoparticles with PVP and treated them with tetraethylorthosilicate in basic ethanol to obtain MOF@silica core/shell nanostructures for controlled release of drugs. Sadr et al. also fabricated magnetic $\mathrm{Fe}_{3} \mathrm{O}_{4} @$ silica@MIL-100(Fe) particles and modified the surface by grafting cyclodextrin for controlled delivery of cephalexin, an antibiotic drug [42]. Further modifications should be conducted to improve the stability, functionality, or biocompatibility of $\mathrm{MOFs} / \mathrm{SiO}_{2}$ composites for drug delivery.

In this work, a facile process was reported by encapsulating MOF nanoparticles with an organosilica layer. The product was directly utilized for drug delivery without further treatment. Polysilsesquioxanes (PSQs), an organosilica with organic/inorganic hybrid structure, have attracted much attention in the field of nanomedicine due to their high stability, biocompatibility, and easy functionalization [40,48]. We first fabricated UiO-66- $\mathrm{NH}_{2}$ nanoparticles, an amine-functionalized MOFs, from $\mathrm{Zr}$ ions and 2-aminoterephthalic acid ligand. We then coated epoxide-functionalized organosilica on $\mathrm{UiO}-66-\mathrm{NH}_{2}$ particles with sodium lignosulfonate as stabilizer and ammonia as catalyst via a controlled sol-gel process in aqueous media (Scheme 1). PSQ layers, as a shell component, offer advantages such as good porous structure, high chemical stability, and good biocompatibility. UiO-66- $\mathrm{NH}_{2} @ E P S Q$ nanocomposites show high drug loading capacity and controlled release of ibuprofen, an anti-inflammatory drug. The MTT assay indicated that drug-free UiO-66- $\mathrm{NH}_{2} @ E P S Q$ nanocomposites demonstrated very low cytotoxicity. This study opens new opportunities to construct a safe and efficient delivery system for a wide range of applications.

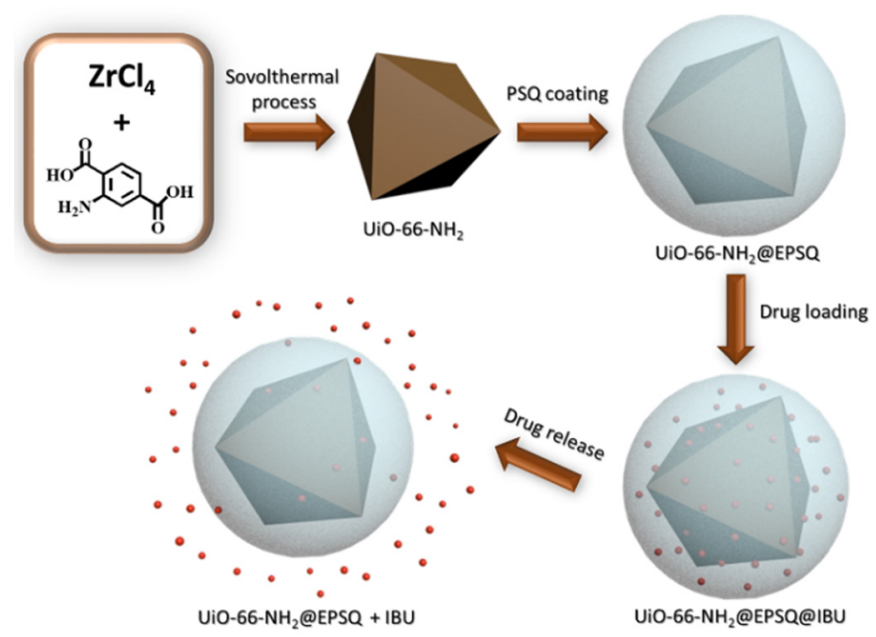

Scheme 1. Preparation of UiO-66- $\mathrm{NH}_{2}$ and $\mathrm{UiO}-66-\mathrm{NH}_{2} @ E P S Q$ for drug delivery. 


\section{Materials and Methods}

\subsection{Materials}

2-Aminoterephthalic acid (98\%) and polyvinylpyrrolidone (Mw avg. $=40,000)$ were purchased from Energy Chemical. (Energy Chemical, Shanghai, China). $\mathrm{ZrCl}_{4}$ (98\%), sodium lignosulfonate, ammonia (AR, 25-28\%), $\gamma$-(2,3-epoxypropoxy)propytrimethosysilane (97\%), methanol (99.5\%), ethanol (AR), Sodium chloride (for cell culture, for insect cell culture, $\geq 99.5 \%$ ), Sodium phosphate dibasic dodecahydrate (GR, 99\%), Potassium phosphate monobasic (for cell culture, for insect cell culture, $\geq 99 \%$ ), Potassium chloride (for cell culture, $\geq 99.5 \%$ ) and ibuprofen (GC, $\geq 98 \%$ ) were supplied by Aladdin Reagents Co., Ltd. (Aladdin Reagents Co., Ltd., Shanghai, China). Acetic acid (AR, $\geq 99.5 \%$ ) was purchased from Sinopharm Chemical Reagent Co., Ltd. (Sinopharm Chemical Reagent Co., Ltd, Shanghai, China). Fetal bovine serum was supplied by Bovogen Biological. (Bovogen Biologicals, C0230, Brazil). Dulbecco's Modified Eagle's Medium (DMEM) and trypsin-EDTA solution (0.25\%, phenol red) were purchased from Invitrogen Gibco. (Invitrogen Gibco, Carlsbad, CA, US). Penicillin-streptomycin liquid $(100 \times)$ and trypsin-EDTA were supplied by Beijing Solarbio Technology Co., Ltd. (Beijing Solarbio Technology Co., Ltd, Beijing, China). 3-(4,5-Dimethyl-2-thiazolyl)-2,5-diphenyl-2-H-tetrazolium bromide (MTT) was purchased from MedChemexpress CO., Ltd. (MedChemexpress CO., Ltd, HY-15924, NJ, US). All chemicals were used directly without further purification.

\subsection{Characterization}

Fourier transform infrared spectroscopy (FTIR) using $\mathrm{KBr}$ powder-pressed pellets with approximately $1 \mathrm{wt}$ \% of the sample was recorded on a Perkin-Elmer Spectrum GX-spectrophotometer (Waltham, MA, US) with a spectral resolution of $1 \mathrm{~cm}^{-1}$ and scan number of 32. The morphology of all samples was observed by scanning electron microscopy (SEM) using a FEI-SEM system (FEI Helios Nanolab 600i, Hillsboro, OR, US) operating at 5 kV. For particle size estimation, more than 100 particles on the SEM images were averaged. Transmission electron microscopy (TEM) images were obtained using a FEI Tecnai G2F30 electron microscope (FEI, Hillsboro, OR, US) operating at $200 \mathrm{kV}$. The X-ray diffraction (XRD) pattern of the samples was recorded using a X PertPowder (PANalytical B.V., Almelo, Netherlands). The X-ray tube was operated at $40 \mathrm{kV}$ and $40 \mathrm{~mA}(\mathrm{Cu} \mathrm{K} \alpha$ radiation with Ni filter, $\lambda=1.5406 \AA$ ). UV-visible spectra were recorded using the Evolution 201 (Thermo, Waltham, MA, US) UV-Visible spectrophotometer with $1 \mathrm{~cm}$ quartz cuvettes.

\subsection{Synthesis of UiO-66-NH $\mathrm{H}_{2} @ E P S Q$ Core/Shell Nanocomposite Materials}

$\mathrm{UiO}-66-\mathrm{NH}_{2}$ nanoparticles were prepared according to the procedure reported in literature [49]. Typically, $0.0628 \mathrm{~g}$ of $\mathrm{ZrCl}_{4}(0.34 \mathrm{mmol}, 98 \%)$ and $0.0808 \mathrm{~g}$ of 2-aminoterephthalic acid $(0.34 \mathrm{mmol}, 98 \%)$ were added into blue-capped bottles with $100 \mathrm{~mL}$ of DMF. The bottle was then injected with $0.6 \mathrm{~mL}$ of acetic acid (glacial). The system was stirred for $24 \mathrm{~h}$ at $100{ }^{\circ} \mathrm{C}$ in an oil bath. After the reaction, the nanoparticles were separated by centrifugation and washed with DMF three times and with distilled water three times. Light brown UiO-66- $\mathrm{NH}_{2}$ nanoparticles were obtained after freeze drying.

The as-prepared UiO-66- $\mathrm{NH}_{2}$ nanoparticles $(0.2 \mathrm{~g})$ were dispersed in the mixture of $80 \mathrm{~mL}$ of methanol and $66 \mathrm{~mL}$ of water and ultrasonicated for $6 \mathrm{~h}$. The system was combined with $0.2 \mathrm{~g}$ of sodium ligninsulfonate and $2 \mathrm{~g}$ of PVP and stirred for $10 \mathrm{~min}$ at room temperature. The suspension was transferred to an ice bath and stirred for $10 \mathrm{~min}$. The suspension was combined with $4 \mathrm{~mL}$ of ammonia solution and dropwise with $1 \mathrm{mmol}$ (for nanocomposites A), $2 \mathrm{mmol}$ (for nanocomposites B), or $3 \mathrm{mmol}$ (for nanocomposites C) $\gamma$-glycidyloxypropyltrimethoxysilane. The suspension was first stirred for $6 \mathrm{~h}$ in an ice bath and stirred for $12 \mathrm{~h}$ at room temperature. After the reaction, the nanoparticles were separated by centrifugation and washed three times with methanol and water. The final core/shell structured UiO-66- $\mathrm{NH}_{2} @ E P S Q$ nanocomposites were obtained after freeze drying. 


\subsection{Drug Loading and Release}

Ibuprofen loading: According to the weight ratio of $W_{\text {drug }} / W_{\text {carrier }}$ listed in Table 1 , a certain amount of ibuprofen and corresponding amount of UiO-66- $\mathrm{NH}_{2} @ E P S Q$ nanoparticles were added into a vial containing $3 \mathrm{~mL}$ of ethanol and $7 \mathrm{~mL}$ of water. The system was first stirred for $6 \mathrm{~h}$ at $37^{\circ} \mathrm{C}$ and stirred overnight at room temperature. The system was transferred to a dialysis bag with a molecular weight cut off of $3500 \mathrm{Da}$ and immersed in $200 \mathrm{~mL}$ of deionized water for $12 \mathrm{~h}$ with gentle stirring at room temperature to form drug-loaded particle suspensions for the next step.

Table 1. Materials and dosage of drug loading experiment.

\begin{tabular}{cccc}
\hline Code & $\boldsymbol{W}_{\text {drug }} / \boldsymbol{W}_{\text {carrier }}$ & Ibuprofen & UiO-66-NH $\mathbf{H E P S Q}_{\mathbf{2}}$ E \\
\hline${ }^{1} \mathrm{~A} 1$ & 0.5 & $0.0020 \mathrm{~g}$ & $0.0042 \mathrm{~g}$ \\
$\mathrm{~A} 2$ & 1.0 & $0.0041 \mathrm{~g}$ & $0.0041 \mathrm{~g}$ \\
$\mathrm{~A} 3$ & 2.0 & $0.0081 \mathrm{~g}$ & $0.0041 \mathrm{~g}$ \\
${ }^{2} \mathrm{~B} 1$ & 0.5 & $0.0020 \mathrm{~g}$ & $0.0044 \mathrm{~g}$ \\
$\mathrm{~B} 2$ & 1.0 & $0.0042 \mathrm{~g}$ & $0.0043 \mathrm{~g}$ \\
$\mathrm{~B} 3$ & 2.0 & $0.0080 \mathrm{~g}$ & $0.0042 \mathrm{~g}$ \\
${ }^{3} \mathrm{C} 1$ & 0.5 & $0.0022 \mathrm{~g}$ & $0.0043 \mathrm{~g}$ \\
$\mathrm{C} 2$ & 1.0 & $0.0044 \mathrm{~g}$ & $0.0043 \mathrm{~g}$ \\
C3 & 2.0 & $0.0083 \mathrm{~g}$ & $0.0042 \mathrm{~g}$ \\
\hline
\end{tabular}

${ }^{1} \mathrm{~A} 1-\mathrm{A} 3$ was loaded with nanocomposites $\mathrm{A} ;{ }^{2} \mathrm{~B} 1-\mathrm{B} 3$ was loaded with nanocomposites $\mathrm{B} ;{ }^{3} \mathrm{C} 1-\mathrm{C} 3$ was loaded with nanocomposites $C$.

In vitro release: the dialysis bag was rinsed with water and then put into the PBS solution (pH 7.4). In intro drug release tests with ibuprofen on the UiO-66- $\mathrm{NH}_{2} @ E P S Q$ nanoparticles were performed with gentle stirring at room temperature. $3 \mathrm{~mL}$ of PBS solution was taken out from the released external solution at regular intervals, and then $3 \mathrm{~mL}$ of fresh PBS solution was added to keep the volume of the external solution constant. The absorbance of the PBS solution taken out from the released external solution at every interval was recorded with Evolution $201 \mathrm{UV}$-Vis spectrophotometer to determine the drug concentration in the solution. The cumulative release amount of the drugs was estimated by the concentration of ibuprofen in the solution.

\subsection{Stability Test and Cytotoxicity Study}

The stability test of UiO-66- $\mathrm{NH}_{2} @ E P S Q$ nanocomposites in PBS solution ( $\mathrm{pH} 7.4$ ) was conducted as follows: UiO-66- $\mathrm{NH}_{2} @ E P S Q$ nanocomposites $(0.2 \mathrm{~g})$ were well dispersed in $20 \mathrm{~mL}$ PBS solution under vigorous stirring and soaked for $1,3,5$ and $7 \mathrm{~d}$ at room temperature. The samples were separated by centrifugation, washed twice with water and finally the dry powders were obtained after freeze drying process. FTIR technique was utilized to characterize the stability of the materials after soaking in PBS solution.

The cytotoxicity of nanocomposite A, B, and C was assessed by MTT assay. HeLa cells were provided by Shanghai cell bank (Chinese Academy of Sciences, Shanghai, China). $5 \times 10^{3}$ cells/well of HeLa cells were seeded in 96-well plate and incubated in Dulbecco's Modified Eagle's Medium (DMEM) supplemented with 10\% fetal bovine serum, 1\% Penicillin-Streptomycin for $24 \mathrm{~h}$ before treated by the composites. Then, nanocomposite A, B, and C with different concentrations $(10,50$, and $100 \mu \mathrm{g} / \mathrm{mL}$ ) were added into $100 \mu \mathrm{L}$ culture medium and co-cultured with HeLa cells for $24 \mathrm{~h}, 48 \mathrm{~h}$ and $72 \mathrm{~h}$ respectively. Culture medium without composites was used as a blank control. Subsequently, cells were washed with PBS twice, and added $200 \mu \mathrm{L}$ culture medium and $0.5 \mathrm{mg} / \mathrm{mL}$ MTT solution to each well to be incubated for $4 \mathrm{~h}$. Then the MTT-medium mixture was removed and $150 \mu \mathrm{L}$ of DMSO was added to each well and vibrated for $10 \mathrm{~min}$ to fully dissolve the formazan crystals. The absorbance of the above DMSO solution at $570 \mathrm{~nm}$ was measured by a microplate reader (EPOCH2T, Bio-tek, VT, US). The cell viability was calculated as follows: viability $(\%)=$ (mean absorbance value of treatment group/mean absorbance value of control $) \times 100 \%$. All samples were analyzed in triplicate. 
Cell viability was further analyzed with the Live/Dead cell staining kit (BB4126-1, Best Bio, Shanghai, China). $1 \times 10^{4}$ /well of Hela cells were seeded into 24 -well plate, and treated by nanocomposite A, $\mathrm{B}$, and $\mathrm{C}$ with different concentrations $\left(10,50\right.$, and $\left.100 \mu \mathrm{g} \mathrm{mL}{ }^{-1}\right)$ for $72 \mathrm{~h}$, and stained with $2 \mu \mathrm{M}$ Calcein-AM and $4 \mu \mathrm{M}$ PI for $30 \mathrm{~min}$ at room temperature. Cells were finally observed with fluorescence microscopy (Leica, DMI8, Weztlar, Germany) and analyzed with Image-Pro Plus software (Media Cybernetics, Bethesda, MD, USA).

\section{Results and Discussion}

\subsection{Synthesis and Characterization of UiO-66- $\mathrm{NH}_{2} @ E P S Q$}

$\mathrm{UiO}-66-\mathrm{NH}_{2}$, a kind of MOF built from $\left[\mathrm{Zr}_{6} \mathrm{O}_{4}(\mathrm{OH})_{4}\right]$ octahedron clusters and 2-aminoterephthalic acid ligands, has received considerable attention because of its promising chemical and physical properties and potential applications in drug delivery [50-52]. As shown in Figure 1a, $\mathrm{UiO}^{-66}-\mathrm{NH}_{2}$ nanoparticles with regular octahedron structure and size of approximately $90 \mathrm{~nm}$ were prepared via a solvothermal process using $\mathrm{ZrCl}_{4}$ reacted with 2-aminoterephthalic acid. UiO-66- $\mathrm{NH}_{2} @ E P S Q$ composites were fabricated by the hydrolysis-condensation of organosilane precursor on the surface of UiO-66- $\mathrm{NH}_{2}$ nanoparticles. After coating with the organosilica layer, UiO-66- $\mathrm{NH}_{2} @ E P S Q$ particles with clear spherical shape and diameter of approximately 110-120 nm were obtained with the organosilica shell having a thickness of approximately 10-15 nm (Figure 1b-d). The coating of the organosilica layer on UiO-66- $\mathrm{NH}_{2}$ particles was confirmed by the TEM images (Figure 2), with the core shell structure could be clearly figured out.

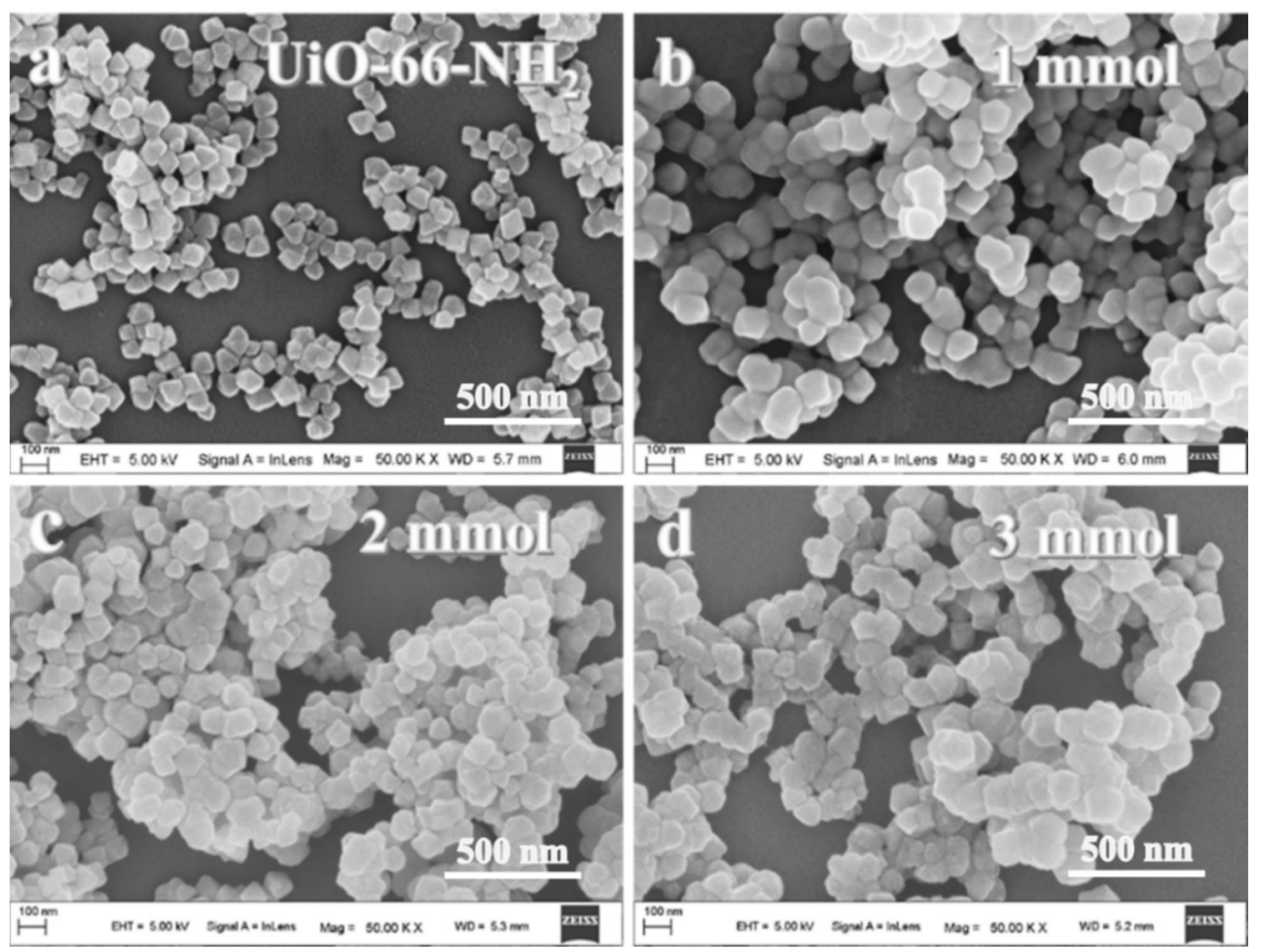

Figure 1. SEM images of (a) UiO-66- $\mathrm{NH}_{2}$ nanoparticles and $(\mathbf{b}-\mathbf{d})$ UiO-66- $\mathrm{NH}_{2} @ E P S Q$ nanoparticles A (1 $\mathrm{mmol}$ ), B (2 mmol), and C (3 mmol), respectively. (UiO-66- $\mathrm{NH}_{2} @ E P S Q$ nanoparticles A, B, C stand for 0.2 g UiO-66- $\mathrm{NH}_{2}$ coated separately with $1 \mathrm{mmol}, 2 \mathrm{mmol}, 3 \mathrm{mmol} \gamma$-glycidyloxypropyltrimethoxysilane). 

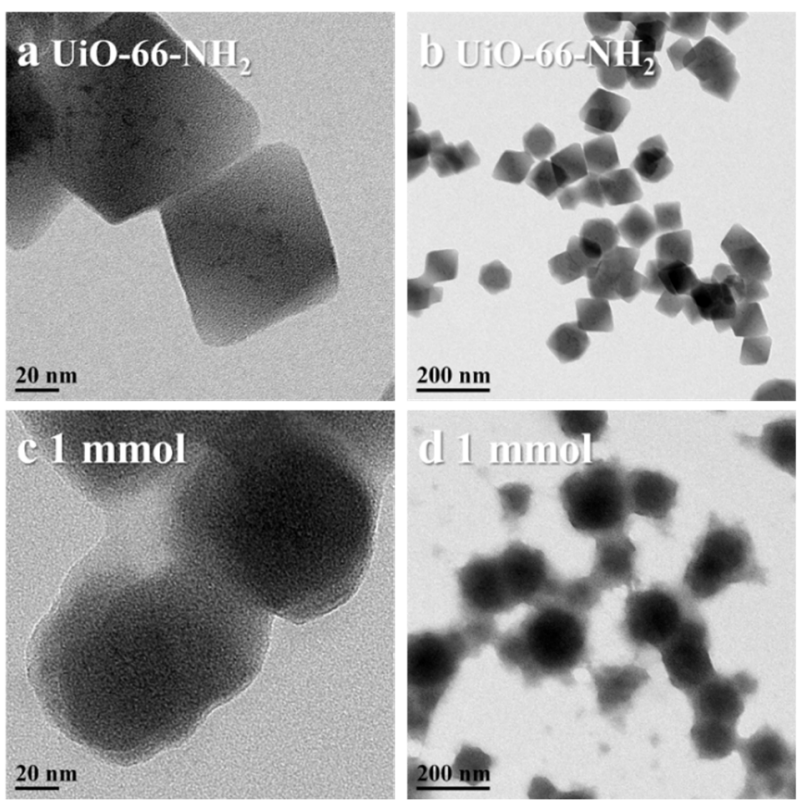

Figure 2. TEM images of (a,b) UiO-66- $\mathrm{NH}_{2}$ nanoparticles and (c,d) UiO-66- $\mathrm{NH}_{2} @ E P S Q$ nanoparticles.

In the FTIR spectra shown in Figure 3, the characteristic peak at $3400 \mathrm{~cm}^{-1}$ is assigned to the $-\mathrm{NH}_{2}$ group on UiO-66- $\mathrm{NH}_{2}$ particles and the peak at $1258 \mathrm{~cm}^{-1}$ represents the stretching vibration of $\mathrm{C}-\mathrm{N},[53,54]$, which becomes weaker after wrapping with PSQ. For the spectra of UiO-66-NH $\mathrm{NH}_{2} @ \mathrm{EPSQ}$ (Figure 3b-d), the characteristic absorption peaks of Si-O-Si appear at 1039 and $1095 \mathrm{~cm}^{-1}$ [55]. After coating with PSQ, the peak shape of the stretching modes of the carboxylic groups in the $\mathrm{NH}_{2}-\mathrm{BDC}$ ligand at 1436 and $1385 \mathrm{~cm}^{-1}$ becomes similar to that of UiO-66, which could be due to the decrease in the $-\mathrm{NH}_{2}$ functional group [56]. No obvious peaks were found within $900-980 \mathrm{~cm}^{-1}$ for the characteristic absorption peak of epoxy functional, which resulted from the ring-opening reaction occurred between the $-\mathrm{NH}_{2}$ group from UiO-66- $\mathrm{NH}_{2}$ and the epoxy groups from EPSQ.

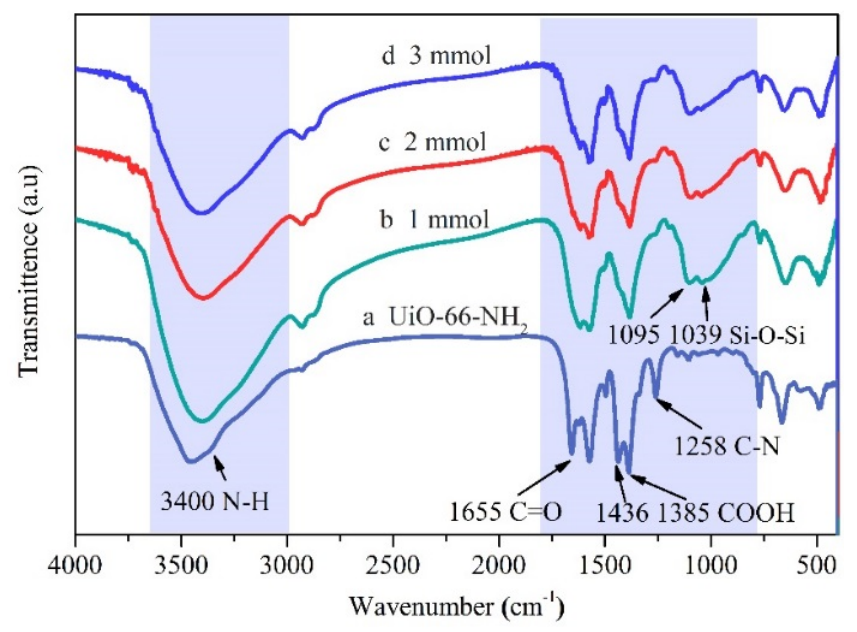

Figure 3. FTIR spectra of UiO-66- $\mathrm{NH}_{2}$ and $\mathrm{UiO}-66-\mathrm{NH}_{2} @ E P S Q$ nanocomposites.

The XRD pattern demonstrated the high crystallinity of the as-prepared UiO-66- $\mathrm{NH}_{2}$ (Figure 4). The strong peaks at $-5^{\circ}$ and $-8^{\circ}$ are consistent with the XRD pattern of the UiO-66- $\mathrm{NH}_{2}$ framework [57]. The high intensity of the XRD characteristic peaks indicates a highly crystalline structure for UiO-66- $\mathrm{NH}_{2}$ synthesized by the solvothermal process. For the XRD pattern of UiO-66- $\mathrm{NH}_{2} @ E P S Q$, two strong peaks were found within $5^{\circ}-8^{\circ}$, and all other peaks became weak or disappeared after wrapping with 
EPSQ. This finding is mainly due to the amorphous organosilica material coated on the outer layer of $\mathrm{UiO}-66-\mathrm{NH}_{2}$.

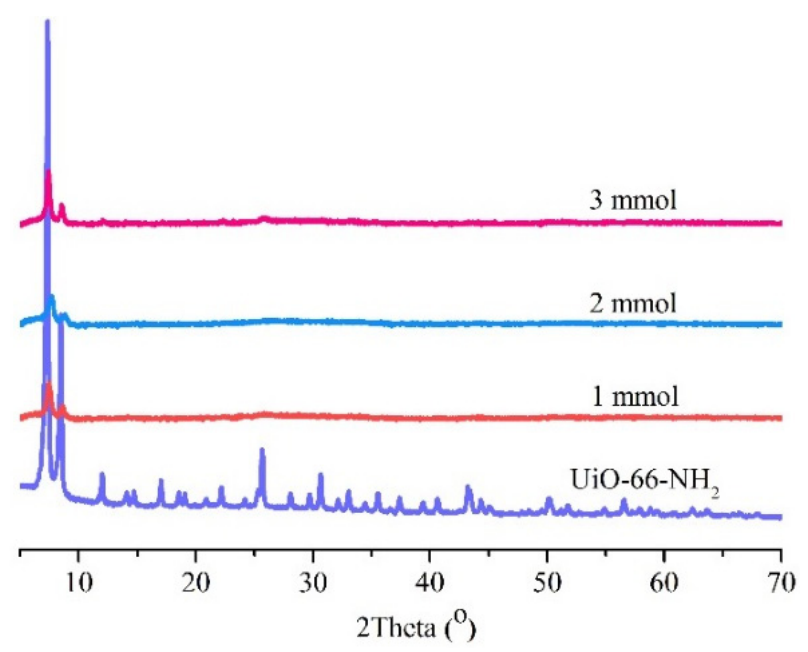

Figure 4. PXRD pattern of UiO-66- $\mathrm{NH}_{2}$ and $\mathrm{UiO}-66-\mathrm{NH}_{2} @ E P S Q$ nanocomposites.

\subsection{Loading and Release Behavior of Ibuprofen with UiO-66- $\mathrm{NH}_{2} @ E P S Q$ as Carriers}

Ibuprofen, a typical anti-inflammatory drug, was introduced into the UiO-66- $\mathrm{NH}_{2} @ E P S Q$ nanocomposite to explore its capabilities as a drug carrier. The drug loading characteristics of the particles prepared from different amounts of organosilane precursors are shown in Table 2. The samples showed high drug capacity. Drug loading efficiency (DLE) and drug encapsulation efficiency (DEE) are used to estimate the drug capacity of carriers. DLE is defined as the ratio of the amount of drug in the nanoparticle to the total amount of the nanoparticles [58]. DEE is defined as the ratio of the amount of drug in the nanoparticle to the total amount of drug added for the preparation [59]. For all samples, DLE is basically close to the input ratio. When the input ratio is 50\%, the DLE is above $46 \%$; when the input ratio is $100 \%$, the DLE is above $98 \%$; when the input ratio is 200\%, the DEL is above 193\%. Meanwhile, the DEEs for all samples are basically above $97 \%$. The high drug loading capacity of composite carriers is thought to be partially attributed to the interaction between amino or epoxy groups on the carriers and carboxylic groups on ibuprofen molecules.

$$
\begin{aligned}
& D L E=\frac{m_{d}-m_{f}}{m_{p}} \times 100 \% \\
& D E E=\frac{m_{d}-m_{f}}{m_{d}} \times 100 \% \\
& E_{r}=\frac{V_{e} \sum_{i=1}^{n-1} C_{i}+V_{0} C_{n}}{m_{d}}
\end{aligned}
$$

In Formulas (1)-(3): DLE: drug loading efficiency, \%; DEE: drug encapsulation efficiency, \%; $E_{r}$ : cumulative drug release, $\% ; m_{d}$ : total amount of drug added for the preparation, mg; $m_{f}$ : amount of drug in the nanoparticle, $\mathrm{mg} ; m_{p}$ : total amount of nanoparticles, $\mathrm{mg} ; V_{e}$ : supplementary PBS solution volume, $3 \mathrm{~mL} ; C_{i}$ : drug concentration in the release solution during the ith replacement, $\mathrm{mg} / \mathrm{mL} ; V_{0}$ : volume of the release solution, $\mathrm{mL} ; C_{n}$ : drug concentration in the release solution during the $(i+1)$ th replacement, $\mathrm{mg} / \mathrm{mL}$; and $n$ : total number of samples. 
Table 2. Drug loading parameters of UiO-66- $\mathrm{NH}_{2} @ E P S Q$ composite with different $W_{\mathrm{drug}} / W_{\text {carrier }}$ ratios.

\begin{tabular}{cccccccc}
\hline \multirow{2}{*}{$\mathbf{i}^{\mathbf{1}}$} & $\boldsymbol{W}_{\text {drug }} / \boldsymbol{W}_{\text {carrier }}$ & \multicolumn{3}{c}{ DLE } & \multicolumn{3}{c}{$\mathbf{D E E}$} \\
\cline { 3 - 8 } & & $\mathbf{A i}$ & $\mathbf{B i}$ & $\mathbf{C i}$ & $\mathbf{A i}$ & $\mathbf{B i}$ & $\mathbf{C i}$ \\
\cline { 3 - 8 } & & $\mathbf{1} \mathbf{~ m m o l}$ & $\mathbf{2} \mathbf{~ m m o l}$ & $\mathbf{3} \mathbf{~ m m o l}$ & $\mathbf{1} \mathbf{~ m m o l}$ & $\mathbf{2} \mathbf{~ m m o l}$ & $\mathbf{3} \mathbf{~ m m o l}$ \\
\hline 1 & $50.0 \%$ & $46.6 \%$ & $46.6 \%$ & $50.1 \%$ & $97.9 \%$ & $97.9 \%$ & $97.9 \%$ \\
2 & $100.0 \%$ & $98.5 \%$ & $98.5 \%$ & $100.1 \%$ & $98.5 \%$ & $98.5 \%$ & $97.9 \%$ \\
3 & $200.0 \%$ & $193.1 \%$ & $193.1 \%$ & $193.5 \%$ & $97.7 \%$ & $97.7 \%$ & $97.9 \%$ \\
\hline
\end{tabular}

${ }^{1}$ A1-A3 was loaded with nanocomposites A; B1-B3 was loaded with nanocomposites B; C1-C3 was loaded with nanocomposites $\mathrm{C}$.

Figure 5 shows the release behavior of ibuprofen from UiO-66-NH $\mathrm{NH}_{2} @ E P S Q$ particles with different nanocomposites (Figure 5a,c,e) at different drug doses (blue, red, and black). The system has a sustained release property. In Figure $5 \mathrm{a}, \mathrm{c}, \mathrm{e}$, the cumulative release of drugs also increased with the maximum release percentage with increasing drug dosage or approximately $80 \%$ for composite $\mathrm{A}$ with $W_{\text {drug }} / W_{\text {carrier }}$ is 2 . With increasing silane precursor, that is, the increase in amine, hydroxyl, epoxy, ether bond, and other functional groups, the cumulative release of $W_{\text {drug }} / W_{\text {carrier }}=2$ shows a decreasing trend. In addition, with the increase of the drug loading amount, the release time prolonged to reach the plateau and it is speculated that longer releases and higher release rates could be achieved by increasing the drug loading amount.
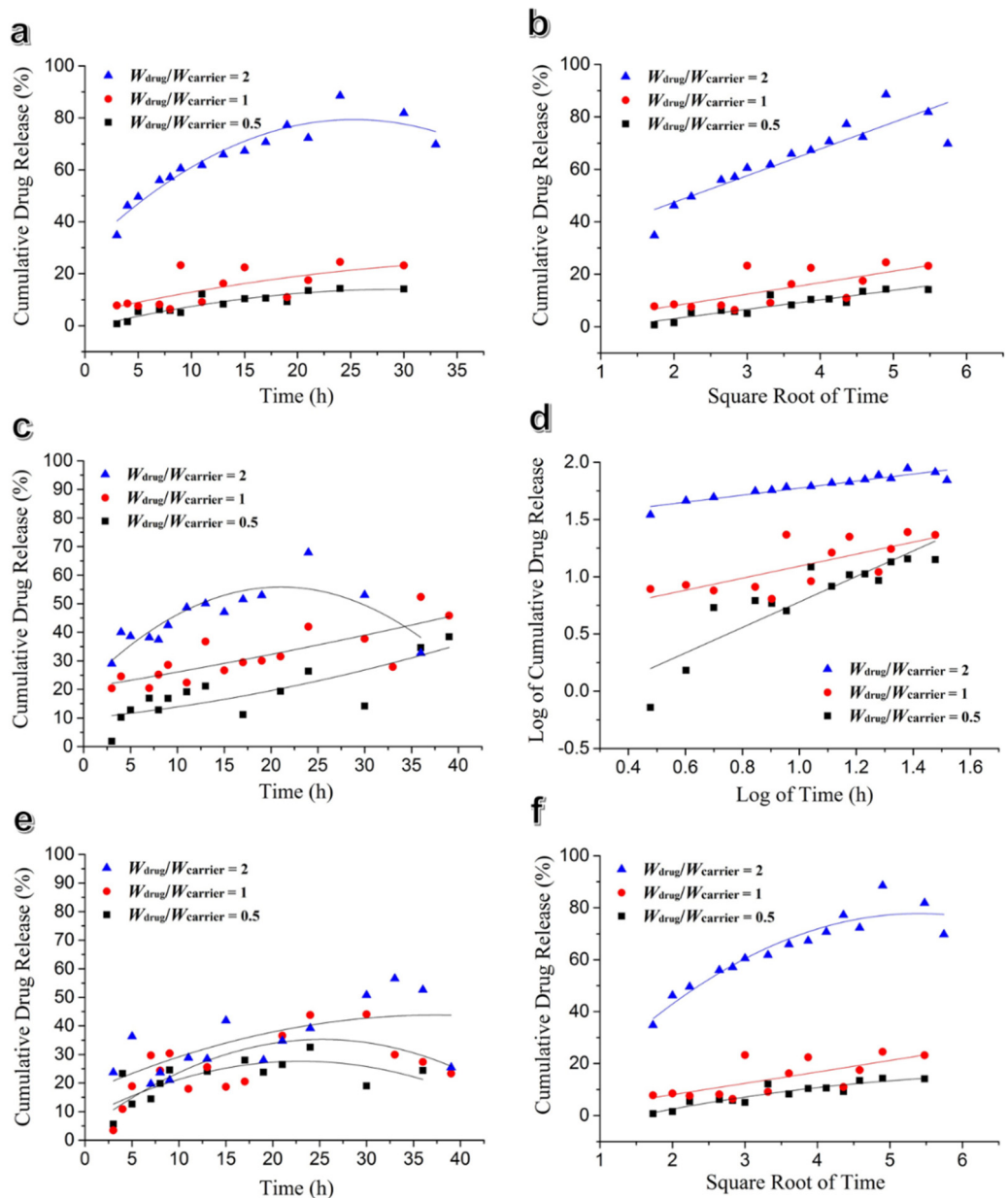

Figure 5. Cumulative release rate-time relationship diagram of the drug loaded with (a) nanocomposites A; (c) nanocomposites B; and (e) nanocomposites C, at different drug doses (blue, red, and black). The kinetic modelling of the drug release from nanocomposites A: (b) Higuchi model; (d) Korsemeyer-Peppas model; and (f) Kopcha model. 
Higuchi model [60]: The model assumes release from an insoluble matrix as a time-dependent progression in which Fickian diffusion is presumed:

$$
M t=\mathrm{k} \sqrt{t}
$$

Korsmeyer-Peppas model $[61,62]$ : The model follows release from a spherical polymeric system in which there may be diffusion or erosion:

$$
M t / M \infty=\mathrm{k} t^{n}
$$

Kopcha model [63]: The model is used to define the amount of diffusion and erosion and their effects on the release rate:

$$
M t=\mathrm{A} \sqrt{t}+B t
$$

in these equations, $M t$ and $M \infty$ represent the amount of drug dissolved at time $t$ and at infinite time, respectively. The kinetic constants are represented by $\mathrm{k}$.

From Figure 5b,d,f and Table 3, it can be concluded that the ibuprofen drug release kinetics from UiO-66- $\mathrm{NH}_{2} @$ EPSQ fitted into Higuchi's mode, indicating that release occurred by diffusion. Correspondingly, a Kopcha's model fitting displayed high A/B values and small B values, indicating release mechanisms were predominantly based on a diffusion process. In addition, the low cumulative release rate/reloaded to the system are believed due to the interaction force between UiO-66- $\mathrm{NH}_{2} @ E P S Q$ and ibuprofen molecules.

Table 3. Parameters obtained by fitting the drug release profiles from the UiO-66- $\mathrm{NH}_{2} @ E P S Q$ with kinetic models.

\begin{tabular}{ccccccccc}
\hline \multirow{2}{*}{$\boldsymbol{W}_{\text {drug }} / \boldsymbol{W}_{\text {carrier }}$} & \multicolumn{2}{c}{ Higuchi } & \multicolumn{3}{c}{ Korsemeyer-Peppas } & \multicolumn{3}{c}{ Kopcha } \\
\cline { 2 - 9 } & $\mathbf{R}^{\mathbf{2}}$ & $\mathbf{k}$ & $\mathbf{R}^{\mathbf{2}}$ & $\mathbf{n}$ & $\mathbf{R}^{\mathbf{2}}$ & $\mathbf{A}$ & $\mathbf{B}$ & $\mathbf{A} / \mathbf{B}$ \\
\hline 0.5 & 0.8346 & 0.03595 & 0.7797 & 1.1137 & 0.8418 & 0.07127 & -0.005 & -14.254 \\
1 & 0.4757 & 0.04387 & 0.5000 & 0.5255 & 0.4233 & 0.04255 & $1.8687 \times 10^{-4}$ & 227.698 \\
2 & 0.7890 & 0.10161 & 0.8654 & 0.3072 & 0.8825 & 0.32482 & -0.03005 & -10.809 \\
\hline
\end{tabular}

\subsection{Stability Test}

Compared with other MOF-based drug carriers, $\mathrm{UiO}-66-\mathrm{NH}_{2}$ has a high degree of connectivity of the metal clusters in the crystal structure, generating exceptional mechanical stability and chemical stability in a broad range of $\mathrm{pH}$ values. In addition, the amino group on the UIO-66- $\mathrm{NH}_{2}$ opens up the possibility of post-modification of UiO-66- $\mathrm{NH}_{2}$ with multiple properties [64-68]. Meanwhile, polysilsesquioxanes (PSQs), an organosilica with organic/inorganic hybrid structure, have high stability, biocompatibility, and easy functionalization [40,48]. Figure 6 shows the FTIR spectra of UiO-66- $\mathrm{NH}_{2}$ and UiO-66- $\mathrm{NH}_{2} @$ EPSQ nanocomposite A, B, and C after soaking in PBS solution ( $\mathrm{pH}$ 7.4) at room temperature for a certain period of time. For the sample of $\mathrm{UiO}-66-\mathrm{NH}_{2}$, after soaking for a week, the absorption peak at $1655 \mathrm{~cm}^{-1}$ assigned for $\mathrm{C}=\mathrm{O}$ obviously decreased sharply (Figure 6a). However, for the FTIR spectra of UiO-66- $\mathrm{NH}_{2} @ E P S Q$ nanocomposites A, B, and C, after soaking for a week, there was no obvious change in each peak. This finding demonstrates that PSQ protected the structure of $\mathrm{UiO}-66-\mathrm{NH}_{2}$.

\subsection{Cytotoxicity Test}

The biocompatibility of the nanoplatform was evaluated by in vitro cytotoxicity assay. Cytotoxicity was investigated by incubating UiO-66- $\mathrm{NH}_{2} @$ EPSQ particles with HeLa cells and assessed using MTT assay and live/dead staining assay at different concentrations $\left(10,50\right.$, and $\left.100 \mu \mathrm{g} \mathrm{mL}^{-1}\right)$. As shown in Figure 7 , the cell viability remains stable even after incubation for $72 \mathrm{~h}$, regardless of the concentration of the particles. In addition, in Figure 8, there were no dead cells (red fluorescence) even treated 
by $100 \mu \mathrm{g} \mathrm{mL}^{-1}$ nanocomposites for $72 \mathrm{~h}$. These results clearly demonstrate that the synthesized UiO-66- $\mathrm{NH}_{2} @ E P S Q$ particles have very low cytotoxicity.
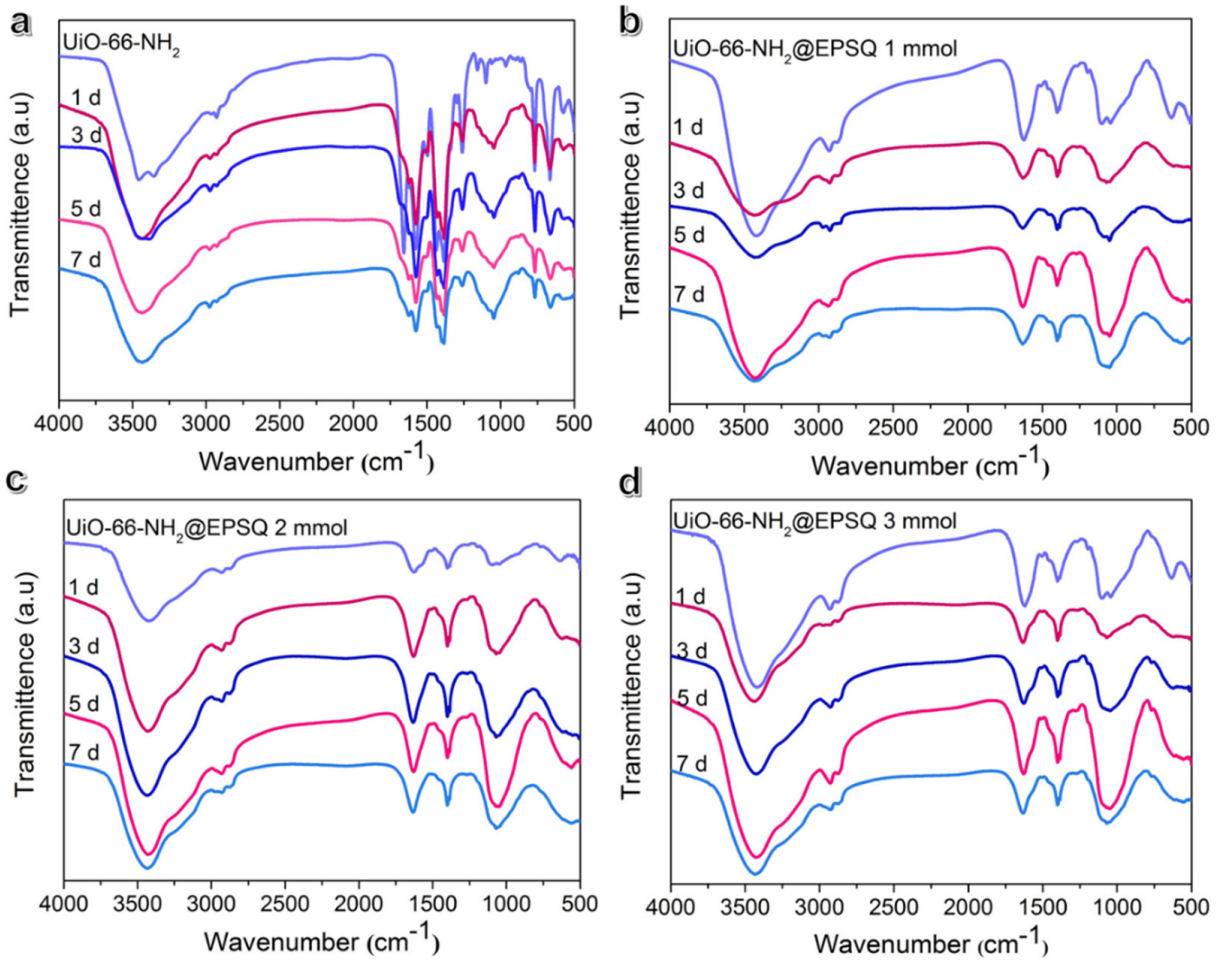

Figure 6. FTIR spectra of (a) UiO-66- $\mathrm{NH}_{2}$, (b) nanocomposites A, (c) nanocomposites $\mathrm{B}$, and (d) nanocomposites $\mathrm{C}$ immersed in PBS solution ( $\mathrm{pH} 7.4$ ) for different times.
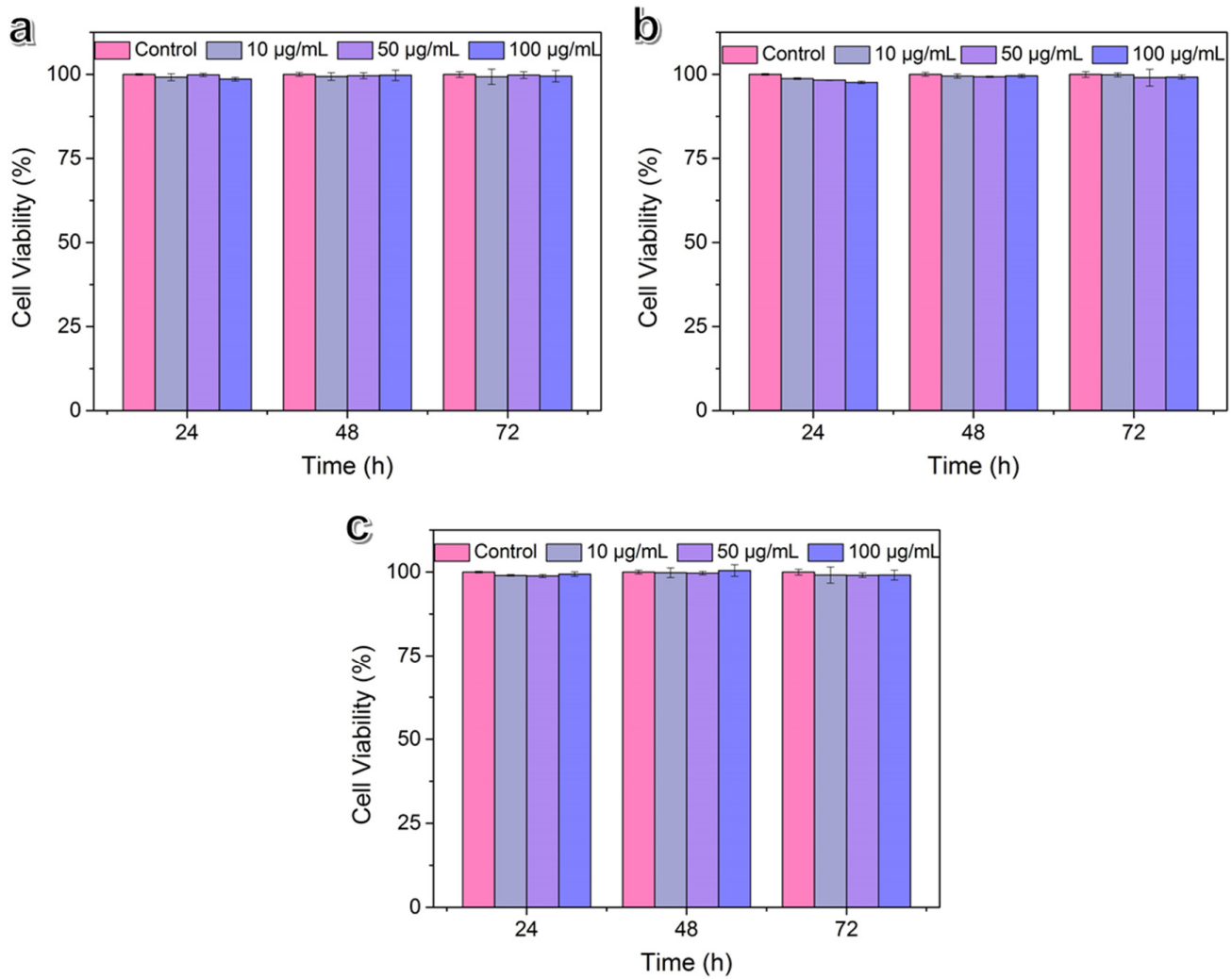

Figure 7. Cytotoxicity test of (a) nanocomposite A, (b) nanocomposite B, (c) nanocomposite C. 
a

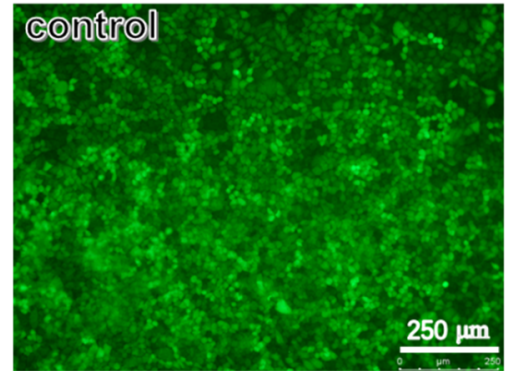

C

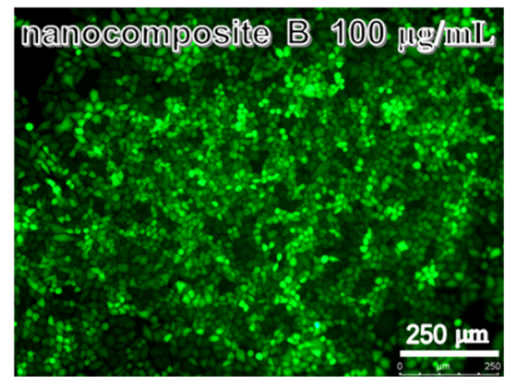

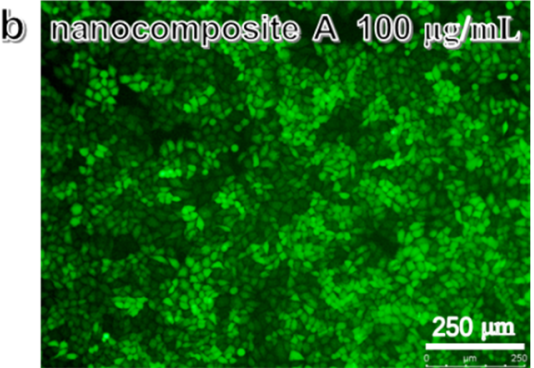

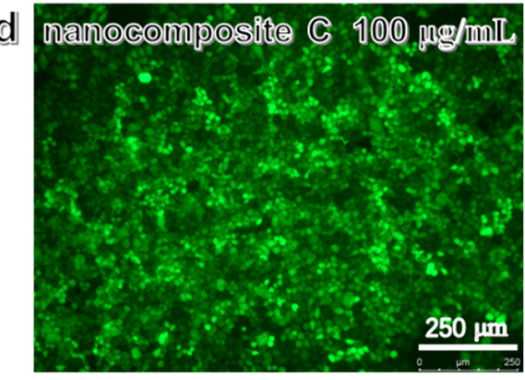

Figure 8. Fluorescent images of Hela cells on (a) control plate, (b) nanocomposite A, (c) nanocomposite $\mathrm{B}$, and (d) nanocomposite $\mathrm{C}$ for $72 \mathrm{~h}$. Among these, live cells were stained green, while dead cells were stained red.

\section{Conclusions}

MOF nanocomposites are currently attracting much attention as newly emerging drug carriers. In this study, we reported a drug delivery system based on the nanocomposite of amine-functionalized MOF (UiO-66- $\mathrm{NH}_{2}$ ) embedded with the active organosilica of PSQ layers. The success of the fabrication was confirmed by FTIR, XRD, SEM and TEM characterizations. The obtained organosilica encapsulated MOF (UiO-66- $\left.\mathrm{NH}_{2} @ E P S Q\right)$ demonstrated high water stability and high drug loading capacity with ibuprofen as a model drug. Ibuprofen from the nanocomposite was also studied. Finally, the preliminary biological studies were performed, which showed that the obtained drug carrier had considerably lower cytotoxicity. We believe that this new nanocomposite delivery system has great potential as a biocompatible system for safe and controlled release of hydrophobic drugs.

Author Contributions: Conceptualization, L.L. (Liangyu Lu), M.M., C.G., H.L., Y.X. and F.D.; Data curation, M.M., C.G., H.L., Y.X. and F.D.; Formal analysis, F.D.; Funding acquisition, Y.X.; Investigation, L.L. (Liangyu Lu), M.M., C.G. and H.L.; Methodology, L.L. (Liangyu Lu); Project administration, F.D.; Software, L.L. (Liangyu Lu); Supervision, F.D.; Writing-original draft, L.L. (Liangyu Lu), L.L. (Long Li) and F.D.; Writing-review \& editing, Y.X., L.L. (Long Li) and F.D. All authors have read and agreed to the published version of the manuscript.

Funding: This research was financially supported by National Natural Science Foundation of China (NSFC No. 51663003, 51663004) and the Science and Technology Department of Guizhou Province ((2019)1092, (2016)123, GZU201625 and YJSCXJH2018071).

Conflicts of Interest: The authors declare no conflict of interest.

\section{References}

1. Thao, T.D.T.; Phuong, H.L.T. Nanoconjugation and encapsulation strategies for improving drug delivery and therapeutic efficacy of poorly water-soluble drugs. Pharmaceutics 2019, 11, 325.

2. Kesse, S.; Boakye-Yiadom, K.O.; Ochete, B.O.; Opoku-Damoah, Y.; Akhtar, F.; Filli, M.S.; Farooq, M.A.; Aquib, M.; Mily, B.J.M.; Murtaza, G.; et al. Mesoporous silica nanomaterials: Versatile nanocarriers for cancer theranostics and drug and gene delivery. Pharmaceutics 2019, 11, 77. [CrossRef] [PubMed]

3. Teleanu, D.M.; Negut, I.; Grumezescu, V.; Grumezescu, A.M.; Teleanu, A.I. Nanomaterials for drug delivery to the central nervous system. Nanomaterials 2019, 9, 371. [CrossRef] [PubMed] 
4. Choi, G.; Kim, T.-H.; Oh, J.-M.; Choy, J.-H. Emerging nanomaterials with advanced drug delivery functions; focused on methotrexate delivery. Coord. Chem. Rev. 2018, 359, 32-51. [CrossRef]

5. Li, J.; Wu, S.; Wu, C.; Qiu, L.; Zhu, G.; Cui, C.; Liu, Y.; Hou, W.; Wang, Y.; Zhang, L.; et al. Versatile surface engineering of porous nanomaterials with bioinspired polyphenol coatings for targeted and controlled drug delivery. Nanoscale 2016, 8, 8600-8606. [CrossRef] [PubMed]

6. Yanes, R.E.; Tamanoi, F. Development of mesoporous silica nanomaterials as a vehicle for anticancer drug delivery. Ther. Deliv. 2012, 3, 389-404. [CrossRef] [PubMed]

7. Aarti; Bhadauria, S.; Nanoti, A.; Dasgupta, S.; Divekar, S.; Gupta, P.; Chauhan, R. $\mathrm{Cu}$-3(btc)(2)-polyethyleneimine: An efficient mof composite for effective $\mathrm{CO}_{2}$ separation. $R S C$ Adv. 2016, 6, 93003-93009. [CrossRef]

8. Duan, G.; Bagheri, A.R.; Jiang, S.; Golenser, J.; Agarwal, S.; Greiner, A. Exploration of macroporous polymeric sponges as drug carriers. Biomacromolecules 2017, 18, 3215-3221. [CrossRef]

9. Hua, D.; Liu, Z.; Wang, F.; Gao, B.; Chen, F.; Zhang, Q.; Xiong, R.; Han, J.; Samal, S.K.; De Smedt, S.C.; et al. $\mathrm{Ph}$ responsive polyurethane (core) and cellulose acetate phthalate (shell) electrospun fibers for intravaginal drug delivery. Carbohydr. Polym. 2016, 151, 1240-1244. [CrossRef]

10. Trofimov, A.D.; Ivanova, A.A.; Zyuzin, M.V.; Timin, A.S. Porous inorganic carriers based on silica, calcium carbonate and calcium phosphate for controlled/modulated drug delivery: Fresh outlook and future perspectives. Pharmaceutics 2018, 10, 167. [CrossRef]

11. Chowdhuri, A.R.; Laha, D.; Chandra, S.; Karmakar, P.; Sahu, S.K. Synthesis of multifunctional upconversion nmofs for targeted antitumor drug delivery and imaging in triple negative breast cancer cells. Chem. Eng. J. 2017, 319, 200-211. [CrossRef]

12. Zhao, H.; Shu, G.; Zhu, J.; Fu, Y.; Gu, Z.; Yang, D. Persistent luminescent metal-organic frameworks with long-lasting near infrared emission for tumor site activated imaging and drug delivery. Biomaterials 2019, 217, 119332. [CrossRef] [PubMed]

13. Han, Y.; Liu, W.; Huang, J.; Qiu, S.; Zhong, H.; Liu, D.; Liu, J. Cyclodextrin-based metal-organic frameworks (cd-mofs) in pharmaceutics and biomedicine. Pharmaceutics 2018, 10, 271. [CrossRef] [PubMed]

14. Su, F.; Jia, Q.; Li, Z.; Wang, M.; He, L.; Peng, D.; Song, Y.; Zhang, Z.; Fang, S. Aptamer-templated silver nanoclusters embedded in zirconium metal-organic framework for targeted antitumor drug delivery. Microporous Mesoporous Mater. 2019, 275, 152-162. [CrossRef]

15. Chowdhury, M.A. Metal-organic-frameworks for biomedical applications in drug delivery, and as mri contrast agents. J. Biomed. Mater. Res. Part A 2017, 105, 1184-1194. [CrossRef]

16. Chiriaco, F.; Soloperto, G.; Greco, A.; Conversano, F.; Ragusa, A.; Menichetti, L.; Casciaro, S. Magnetically-coated silica nanospheres for dual-mode imaging at low ultrasound frequency. World J. Radiol. 2013, 5, 411-420. [CrossRef]

17. Lazaro, I.A.; Haddad, S.; Rodrigo-Munoz, J.M.; Marshall, R.J.; Sastre, B.; del Pozo, V.; Fairen-Jimenez, D.; Forgan, R.S. Surface-functionalization of zr-fumarate mof for selective cytotoxicity and immune system compatibility in nanoscale drug delivery. ACS Appl. Mater. Interfaces 2018, 10, 31146-31157. [CrossRef]

18. Chen, L.; Zhang, J.; Zhou, X.; Yang, S.; Zhang, Q.; Wang, W.; You, Z.; Peng, C.; He, C. Merging metal organic framework with hollow organosilica nanoparticles as a versatile nanoplatform for cancer theranostics. Acta Biomater. 2019, 86, 406-415. [CrossRef]

19. Wu, M.-X.; Yang, Y.-W. Metal-organic framework (mof)-based drug/cargo delivery and cancer therapy. Adv. Mater. 2017, 29. [CrossRef]

20. Horcajada, P.; Chalati, T.; Serre, C.; Gillet, B.; Sebrie, C.; Baati, T.; Eubank, J.F.; Heurtaux, D.; Clayette, P.; Kreuz, C.; et al. Porous metal-organic-framework nanoscale carriers as a potential platform for drug delivery and imaging. Nat. Mater. 2010, 9, 172-178. [CrossRef]

21. Horcajada, P.; Serre, C.; Maurin, G.; Ramsahye, N.A.; Balas, F.; Vallet-Regi, M.; Sebban, M.; Taulelle, F.; Ferey, G. Flexible porous metal-organic frameworks for a controlled drug delivery. J. Am. Chem. Soc. 2008, 130, 6774-6780. [CrossRef] [PubMed]

22. Xia, H.; Wang, J.; Chen, G.; Liu, J.; Wan, G.; Bai, Q. One-pot synthesis of $\mathrm{SiO}_{2} @ \mathrm{SiO}_{2}$ core-shell microspheres with controllable mesopore size as a new stationary phase for fast hplc separation of alkyl benzenes and -agonists. Microchim. Acta 2019, 186. [CrossRef] [PubMed] 
23. Wuttke, S.; Lismont, M.; Escudero, A.; Rungtaweevoranit, B.; Parak, W.J. Positioning metal-organic framework nanoparticles within the context of drug delivery-A comparison with mesoporous silica nanoparticles and dendrimers. Biomaterials 2017, 123, 172-183. [CrossRef] [PubMed]

24. Jiang, K.; Zhang, L.; Hu, Q.; Zhang, X.; Zhang, J.; Cui, Y.; Yang, Y.; Li, B.; Qian, G. A zirconium-based metal-organic framework with encapsulated anionic drug for uncommonly controlled oral drug delivery. Microporous Mesoporous Mater. 2019, 275, 229-234. [CrossRef]

25. Wang, S.; Serre, C. Toward green production of water-stable metal-organic frameworks based on high-valence metals with low toxicities. ACS Sustain. Chem. Eng. 2019, 7, 11911-11927. [CrossRef]

26. Zhu, Q.-L.; Xu, Q. Metal-organic framework composites. Chem. Soc. Rev. 2014, 43, 5468-5512. [CrossRef]

27. Zhang, F.; Liu, L.; Tan, X.; Sang, X.; Zhang, J.; Liu, C.; Zhang, B.; Han, B.; Yang, G. Pickering emulsions stabilized by a metal-organic framework (mof) and graphene oxide (go) for producing mof/go composites. Soft Matter 2017, 13, 7365-7370. [CrossRef]

28. Yang, P.; Liu, Q.; Liu, J.; Zhang, H.; Li, Z.; Li, R.; Liu, L.; Wang, J. Interfacial growth of a metal-organic framework (uio-66) on functionalized graphene oxide (go) as a suitable seawater adsorbent for extraction of uranium(vi). J. Mater. Chem. A 2017, 5, 17933-17942. [CrossRef]

29. Wu, Q.; Wang, J.; Jin, H.; Yan, T.; Yi, G.; Su, X.; Dai, W.; Wang, X. Mof-derived rambutan-like nanoporous carbon/nanotubes/co composites with efficient microwave absorption property. Mater. Lett. 2019, 244, 138-141. [CrossRef]

30. Rao, Z.; Feng, K.; Tang, B.; Wu, P. Surface decoration of amino-functionalized metal organic framework/graphene oxide composite onto polydopamine-coated membrane substrate for highly efficient heavy metal removal. ACS Appl. Mater. Interfaces 2017, 9, 2594-2605. [CrossRef]

31. Qi, X.-L.; Zhou, D.-D.; Zhang, J.; Hu, S.; Haranczyk, M.; Wang, D.-Y. Simultaneous improvement of mechanical and fire-safety properties of polymer composites with phosphonate-loaded mof additives. ACS Appl. Mater. Interfaces 2019, 11, 20325-20332. [CrossRef] [PubMed]

32. Peng, L.; Yang, S.; Sun, D.T.; Asgari, M.; Queen, W.L. Mof/polymer composite synthesized using a double solvent method offers enhanced water and co2 adsorption properties. Chem. Commun. 2018, 54, 10602-10605. [CrossRef] [PubMed]

33. Ma, B.; Guo, H.; Wang, M.; Li, L.; Jia, X.; Chen, H.; Xue, R.; Yang, W. Electrocatalysis of cu-mof/graphene composite and its sensing application for electrochemical simultaneous determination of dopamine and paracetamol. Electroanalysis 2019, 31, 1002-1008. [CrossRef]

34. Xie, S.-M.; Yuan, L.-M. Recent development trends for chiral stationary phases based on chitosan derivatives, cyclofructan derivatives and chiral porous materials in high performance liquid chromatography. J. Sep. Sci. 2019, 42, 6-20. [CrossRef]

35. Gu, J.; Fan, H.; Li, C.; Caro, J.; Meng, H. Robust superhydrophobic/superoleophilic wrinkled microspherical mof@rgo composites for efficient oil-water separation. Angew. Chem. Int. Ed. 2019, 58, 5297-5301. [CrossRef] [PubMed]

36. Ehrling, S.; Kutzscher, C.; Freund, P.; Mueller, P.; Senkovska, I.; Kaskel, S. Mof@SiO 2 core-shell composites as stationary phase in high performance liquid chromatography. Microporous Mesoporous Mater. 2018, 263, 268-274. [CrossRef]

37. Cai, J.; Lu, J.-Y.; Chen, Q.-Y.; Qu, L.-L.; Lu, Y.-Q.; Gao, G.-F. Eu-based mof/graphene oxide composite: A novel photocatalyst for the oxidation of benzyl alcohol using water as oxygen source. New J. Chem. 2017, 41, 3882-3886. [CrossRef]

38. Ma, M.; Lu, L.; Li, H.; Xiong, Y.; Dong, F. Functional metal organic framework/sio2 nanocomposites: From versatile synthesis to advanced applications. Polymers 2019, 11, 1823. [CrossRef]

39. Li, Z.; Zeng, H.C. Armored mofs: Enforcing soft microporous mof nanocrystals with hard mesoporous silica. J. Am. Chem. Soc. 2014, 136, 5631-5639. [CrossRef]

40. Della Rocca, J.; Huxford, R.C.; Comstock-Duggan, E.; Lin, W.B. Polysilsesquioxane nanoparticles for targeted platin-based cancer chemotherapy by triggered release. Angew. Chem. Int. Ed. 2011, 50, 10330-10334. [CrossRef]

41. Prabhu, A.; Al Shoaibi, A.; Srinivasakannan, C. Preparation and characterization of silica aerogel-zif- 8 hybrid materials. Mater. Lett. 2015, 146, 43-46. [CrossRef] 
42. Lajevardi, A.; Sadr, M.H.; Yaraki, M.T.; Badiei, A.; Armaghan, M. A ph-responsive and magnetic $\mathrm{Fe}_{3} \mathrm{O}_{4} @$ silica@mil-100(fe)/beta-cd nanocomposite as a drug nanocarrier: Loading and release study of cephalexin. New J. Chem. 2018, 42, 9690-9701. [CrossRef]

43. Lin, C.; Chi, B.; Xu, C.; Zhang, C.; Tian, F.; Xu, Z.; Li, L.; Whittaker, A.K.; Wang, J. Multifunctional drug carrier on the basis of $3 \mathrm{~d}-4 \mathrm{f}$ fe/la-mofs for drug delivery and dual-mode imaging. J. Mater. Chem. B 2019, 7 , 6612-6622. [CrossRef] [PubMed]

44. Blanco, I. Polysiloxanes in theranostics and drug delivery: A review. Polymers 2018, 10, 755. [CrossRef]

45. Vivero-Escoto, J.L.; Rieter, W.J.; Lau, H.; Huxford-Phillips, R.C.; Lin, W.B. Biodegradable polysilsesquioxane nanoparticles as efficient contrast agents for magnetic resonance imaging. Small 2013, 9, 3523-3531. [CrossRef]

46. Della Rocca, J.; Liu, D.; Lin, W. Nanoscale metal-organic frameworks for biomedical imaging and drug delivery. Acc. Chem. Res. 2011, 44, 957-968. [CrossRef]

47. Rieter, W.J.; Taylor, K.M.L.; Lin, W. Surface modification and functionalization of nanoscale metal-organic frameworks for controlled release and luminescence sensing. J. Am. Chem. Soc. 2007, 129, 9852-9853. [CrossRef]

48. Della Rocca, J.; Werner, M.E.; Kramer, S.A.; Huxford-Phillips, R.C.; Sukumar, R.; Cummings, N.D.; Vivero-Escoto, J.L.; Wang, A.Z.; Lin, W.B. Polysilsesquioxane nanoparticles for triggered release of cisplatin and effective cancer chemoradiotherapy. Nanomed. Nanotechnol. Biol. Med. 2015, 11, 31-38. [CrossRef]

49. Xu, Y.M.; Japip, S.; Chung, T.-S. Mixed matrix membranes with nano-sized functional uio-66-type mofs embedded in 6fda-hab/daba polyimide for dehydration of c1-c3 alcohols via pervaporation. J. Membr. Sci. 2018, 549, 217-226. [CrossRef]

50. Cunha, D.; Gaudin, C.; Colinet, I.; Horcajada, P.; Maurin, G.; Serre, C. Rationalization of the entrapping of bioactive molecules into a series of functionalized porous zirconium terephthalate mofs. J. Mater. Chem. B 2013, 1, 1101-1108. [CrossRef]

51. Devautour-Vinot, S.; Diaby, S.; da Cunha, D.; Serre, C.; Horcajada, P.; Maurin, G. Ligand dynamics of drug-loaded microporous zirconium terephthalates-based metal-organic frameworks: Impact of the nature and concentration of the guest. J. Phys. Chem. C 2014, 118, 1983-1989. [CrossRef]

52. Devautour-Vinot, S.; Martineau, C.; Diaby, S.; Ben-Yahia, M.; Miller, S.; Serre, C.; Horcajada, P.; Cunha, D.; Taulelle, F.; Maurin, G. Caffeine confinement into a series of functionalized porous zirconium mofs: A joint experimental/modeling exploration. J. Phys. Chem. C 2013, 117, 11694-11704. [CrossRef]

53. DeCoste, J.B.; Peterson, G.W. Processing of metal-organic frameworks for air filtration applications. Abstr. Pap. Am. Chem. Soc. 2014, 248.

54. Silva, C.G.; Luz, I.; Llabres i Xamena, F.X.; Corma, A.; Garcia, H. Water stable zr-benzenedicarboxylate metal-organic frameworks as photocatalysts for hydrogen generation. Chem. A Eur. J. 2010, 16, 11133-11138. [CrossRef]

55. Dong, F.; Guo, W.; Chu, S.-W.; Ha, C.-S. Novel fluorinated polysilsesquioxane hollow spheres: Synthesis and application in drug release. Chem. Commun. 2010, 46, 7498-7500. [CrossRef]

56. Xu, X.-Y.; Chu, C.; Fu, H.; Du, X.-D.; Wang, P.; Zheng, W.; Wang, C.-C. Light-responsive uio-66-nh2/ag3po4 mof-nanoparticle composites for the capture and release of sulfamethoxazole. Chem. Eng. J. 2018, 350, 436-444. [CrossRef]

57. Zhang, C.; Li, T.; Song, H.; Han, Y.; Dong, Y.; Wang, Y.; Wang, Q. Improving the thermal conductivity and mechanical property of epoxy composites by introducing polyhedral oligomeric silsesquioxane-grafted graphene oxide. Polym. Compos. 2018, 39, E1890-E1899. [CrossRef]

58. Cai, K.; He, X.; Song, Z.; Yin, Q.; Zhang, Y.; Uckun, F.M.; Jiang, C.; Cheng, J. Dimeric drug polymeric nanoparticles with exceptionally high drug loading and quantitative loading efficiency. J. Am. Chem. Soc. 2015, 137, 3458-3461. [CrossRef]

59. Zhang, Z.; Feng, S.-S. The drug encapsulation efficiency, in vitro drug release, cellular uptake and cytotoxicity of paclitaxel-loaded poly(lactide)-tocopheryl polyethylene glycol succinate nanoparticles. Biomaterials 2006, 27, 4025-4033. [CrossRef]

60. Higuchi, T. Mechanism of sustained-action medication. Theoretical analysis of rate of release of solid drugs dispersed in solid matrices. J. Pharm. Sci. 1963, 52, 1145-1149.

61. Korsmeyer, R.W.; Lustig, S.R.; Peppas, N.A. Solute and penetrant diffusion in swellable polymers. I. Mathematical modeling. J. Polym. Sci. Polym. Phys. Ed. 1986, 24, 395-408. 
62. Richard, W.; Korsmeyer, R.G.; Eric Doelker, P.B.; Nikolaos, A. Peppas Mechanisms of solute release from porous hydrophilic polymers. Int. J. Pharm. 1983, 15, 25-35.

63. Kopcha, M.; Lordi, N.G.; Tojo, K.J. Evaluation of release from selected thermosoftening vehicles. J. Pharm. Pharrnacol 1991, 43, 382-387. [CrossRef] [PubMed]

64. Nagata, S.; Kokado, K.; Sada, K. Metal-organic framework tethering pnipam for on-off controlled release in solution. Chem. Commun. 2015, 51, 8614-8617. [CrossRef] [PubMed]

65. Cavka, J.H.; Jakobsen, S.; Olsbye, U.; Guillou, N.; Lamberti, C.; Bordiga, S.; Lillerud, K.P. A new zirconium inorganic building brick forming metal organic frameworks with exceptional stability. J. Am. Chem. Soc. 2008, 130, 13850-13851. [CrossRef] [PubMed]

66. Katz, M.J.; Brown, Z.J.; Colon, Y.J.; Siu, P.W.; Scheidt, K.A.; Snurr, R.Q.; Hupp, J.T.; Farha, O.K. A facile synthesis of uio-66, uio-67 and their derivatives. Chem. Commun. 2013, 49,9449-9451. [CrossRef]

67. DeStefano, M.R.; Islamoglu, T.; Hupp, J.T.; Farha, O.K. Room-temperature synthesis of uio-66 and thermal modulation of densities of defect sites. Chem. Mater. 2017, 29, 1357-1361. [CrossRef]

68. Gao, X.; Cui, R.; Ji, G.; Liu, Z. Size and surface controllable metal-organic frameworks (mofs) for fluorescence imaging and cancer therapy. Nanoscale 2018, 10, 6205-6211. [CrossRef]

(C) 2020 by the authors. Licensee MDPI, Basel, Switzerland. This article is an open access article distributed under the terms and conditions of the Creative Commons Attribution (CC BY) license (http://creativecommons.org/licenses/by/4.0/). 